\title{
A Proposed Model for Quantification of Ocular Trauma
}

\author{
Bhartendu Shukla \\ Ocular Trauma Department, Ratan Jyoti Ophthalmic Institute, Gwalior, India
}

Email address:

bhartendushukla@yahoo.com

\section{To cite this article:}

Bhartendu Shukla. A Proposed Model for Quantification of Ocular Trauma.International Journal of Ophthalmology \& Visual Science. Vol. 3, No. 3, 2018, pp. 39-42. doi: 10.11648/j.ijovs.20180303.11

Received: September 5, 2018; Accepted: September 27, 2018; Published: October 24, 2018

\begin{abstract}
In general sciences like physics and chemistry it is relatively easy to quantify a value. However in medical science it is not always easy and at times we have to make a compromise. An effort has been made to quantify ocular trauma (eye injuries) based on loss of structure and loss of function. The loss of structure is graded in percentage from a formula and the loss of function is also graded in percentage mainly from loss of vision. Structural loss and functional loss gives total loss. Both are plotted on a graph paper. Recording is done at weekly interval for moderate injuries. For severe injuries it can be done at monthly interval. A horizontal line of $20 \mathrm{~cm}$ is drawn at the bottom of graph paper. From the centre of this line a vertical line of $10 \mathrm{~cm}$ is drawn. Structural damage is noted on the left side of vertical line and the functional damage on the right side at weekly interval for 8 to 10 weeks. At the end of 10 weeks usually a somewhat triangular area is formed which is labeled as ocular traumagram. Each 1 sq.cm.box enclosed in traumagram indicates one Trauma Unit (T.U.) Thus a quantitative value of ocular trauma is obtained. Further details of construction are given in the section of methods. Different types ocular traumagrams are expected in different types of injury.
\end{abstract}

Keywords: Quantification, Ocular Traumagram, Ocular Trauma

\section{Introduction}

Several efforts have been attempted to quantify qualitative data earlier Shukla B, [1], Kuhn F et al [2], Blakes W.D. [3], Shukla B. [4]. An effort had been made to quantify ocular trauma based on loss of structure and loss of function. The loss of structure is graded in percentage from a formula and the loss of function is also graded mainly from the loss of vision in percentage. Loss of structure and loss of function give total loss. Both are plotted on a graph paper at weekly interval for 8 -10 weeks. At the end of 8 weeks a somewhat triangular area is formed which is called ocular traumagram. The number of 1 sq. cm. boxes enclosed are counted. Each sq.cm.represents 1 trauma unit. The total Trauma Units indicate the magnitude of ocular trauma. Many types of traumagram can be anticipated.

\section{Methods}

Loss of structure and function are graded into steps of $10 \%$ on a graph paper on either side of a central line. Structural and functional loss is computed after every one week for moderate injuries for at least 8 weeks. For severe injuries it can be done every month. All recordings are completed on a graph paper with one sq.mm size. squares. Mostly in cases of eye injury the maximum damage (structural or functional) is at the time of injury. A vertical line is drawn up to $10 \mathrm{~cm}$. from the centre of a horizontal line of $20 \mathrm{~cm}$. at the bottom of the graph paper. Structural damage is noted on the left side of vertical line and functional loss on the right side. The horizontal base line drawn indicates the onset of trauma. Another vertical line is drawn on extreme right side also which is divided in 8 parts of $1 \mathrm{~cm}$ each. Each $1 \mathrm{~cm}$. space represents one week. After 8 weeks the upper ends of structural and functional lines are joined. Similarly all points on the left and right side are joined. A somewhat triangular area is formed called ocular traumagram. Each sq.cm.area within this traumagram is counted. Each sq.cm.represents 1 trauma unit (T.U.). Many types of traumagrams can be anticipate. The Ocular Traumagram gives the extent of structural or functional loss in the injured eye. The enclosed area is calculated from counting $1 \mathrm{~mm}$ squares in the enclosed field. Each square represents one trauma unit (1 T.U.). Structural and functional losses are added to give total loss. In bilateral cases the same procedure is repeated in each eye and of both eyes are added to get the total loss of both eyes. In the present paper this is estimated only in 
some common theoretical situations.

Table 1. Evaluation of structural loss.

\begin{tabular}{lllll}
\hline & MILD $=\mathbf{1}$ & MOD. $=\mathbf{2}$ & SEVERE $=\mathbf{3}$ & VERY SEVERE $=\mathbf{4}$ \\
\hline & $\mathbf{5}$ & $\mathbf{1 0}$ & $\mathbf{1 5}$ & $\mathbf{2 0}$ \\
\hline ORBIT \& EYE BALL & & & TOTAL \\
CONJUNCTIVA & & & LOSS \\
CORNEA & & & \\
LIDS & & & \\
LACRIMALAPP. & & & \\
AVERAGE LOSS $=$ TOTALLOSS $/ 5$ & & & \\
\hline
\end{tabular}

Table 2. Evaluation of structural loss.

\begin{tabular}{lll}
\hline Range & Grade & Percentage \\
\hline IF TOTAL IS UPTO 2O T. U. THE LOSS IS & MILD & $20 \%$ \\
IF TOTAL IS 21- 40 T. U. THE LOSS IS & MODERATE & $40 \%$ \\
IF TOTAL IS 41- 60 T.U. THE LOSS IS & SEVERE & $60 \%$ \\
IF TOTAL IS $61-80$ T.U. THE LOSS IS & VERY SEVERE & $80 \%$ \\
IF TOTAL IS $>80$ T.U. THE LOSS IS & TOTAL & $100 \%$ \\
\hline
\end{tabular}

Table 3. Evaluation of functional loss.

\begin{tabular}{lll}
\hline POST TRAUMA V.A. & PERCENTAGE LOSS \\
\hline VA in meter & VA in feet & \\
\hline $6 / 6$ & $20 / 20$ & $0 \%$ \\
$6 / 9$ & $20 / 30$ & $10 \%$ \\
$6 / 12$ & $20 / 40$ & $20 \%$ \\
$6 / 18$ & $20 / 63$ & $30 \%$ \\
$6 / 24$ & $20 / 80$ & $40 \%$ \\
$6 / 36$ & $20 / 125$ & $50 \%$ \\
$6 / 60$ & $20 / 200$ & $60 \%$ \\
$6 / 75$ & $20 / 250$ & $65 \%$ \\
$6 / 95$ & $20 / 320$ & $70 \%$ \\
$6 / 120$ & $20 / 400$ & $75 \%$ \\
$6 / 150$ & $20 / 500$ & $80 \%$ \\
$6 / 190$ & $20 / 630$ & $85 \%$ \\
C.F./ H.M. & C.F. $/$ H.M. & $90 \%$ \\
NO P.L. & NO P.L. & $100 \%$ \\
\hline
\end{tabular}

Table 4. Evaluation of total functional loss.

\begin{tabular}{ll}
\hline PARAMETERS & PERCENTAGE \\
\hline VISUAL ACUITY & $80 \%$ \\
VISUAL FIELD & $05 \%$ \\
OCULARMOTILITY & $05 \%$ \\
OCULARTENSION & $05 \%$ \\
LACRIMALDYSFUNCTION & $05 \%$ \\
TOTAL & $100 \%$ \\
\hline
\end{tabular}

NOTE:

Total loss is calculated in each eye by adding structural andfunctional loss and dividing by 2 .

2. In cases of bilateral injuries the total loss in each eye is added.

\section{Results}

There is no fixed way to know how much structural or functional loss would occur after trauma and how would it vary in the course of time with or without treatment. The following theoretical situations are clinically anticipated:-

A pattern: In most cases of trauma there is maximum structural and functional lossat the time of injury. With passage of time both start diminishing almost equally. If the recovery is complete the two lines exhibiting structural and functional loss may meet at the apex of an isosceles triangle. This is labeled as A pattern of traumagram. This may also be called a standard traumagram.

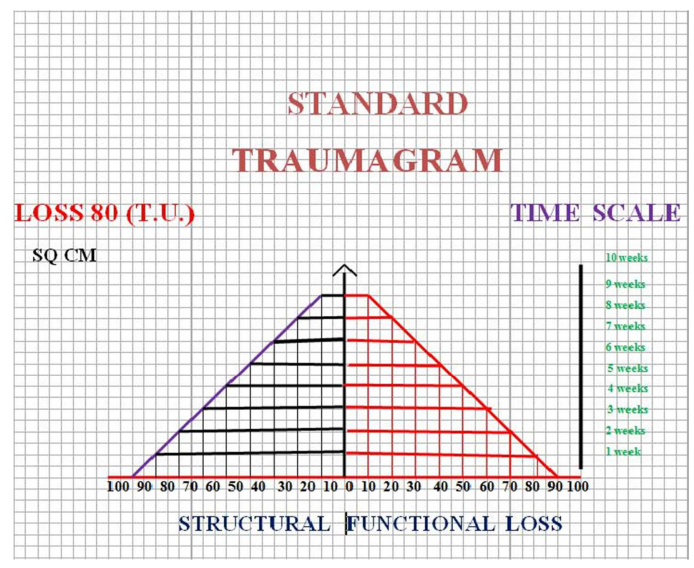

Figure 1. A PATTERN.

$\mathrm{V}$ pattern: Rarely there is minimum structural and functional loss at the beginning of trauma. With passage of time both type of losses may go on increasing. This would result in a $\mathrm{V}$ pattern of traumagram.

\section{INVERSE TRAUMAGRAM}

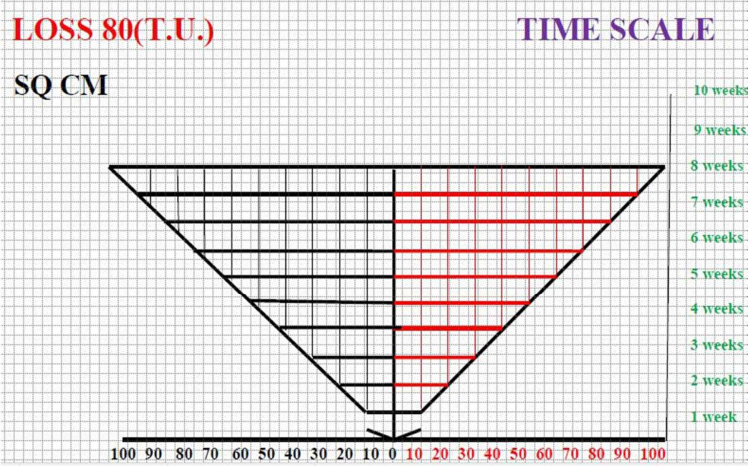

Figure 2. V PATTERN. 
$X$ pattern: Sometimes maximum loss of structure and function is at the beginning. However after some time there is near perfect recovery. Probably due to some complication again there is increase in structural and functional loss. This may result in an $\mathrm{X}$ pattern of traumagram.

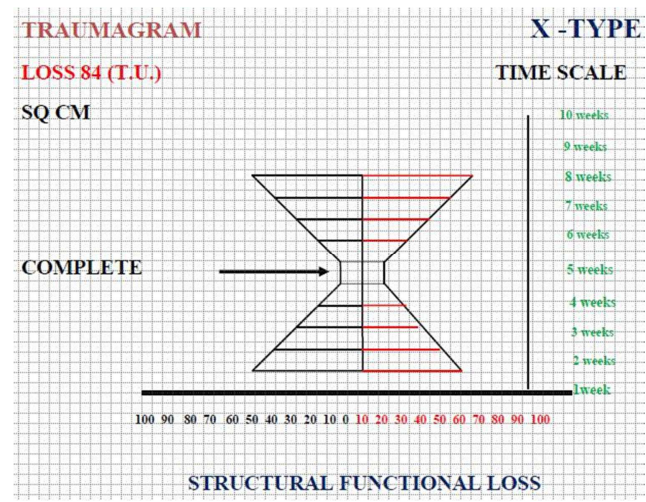

Figure 3. X PATTERN.

Y pattern: Initially there may be no significant change but after some time both structural and functional loss may start appearing and increasing.

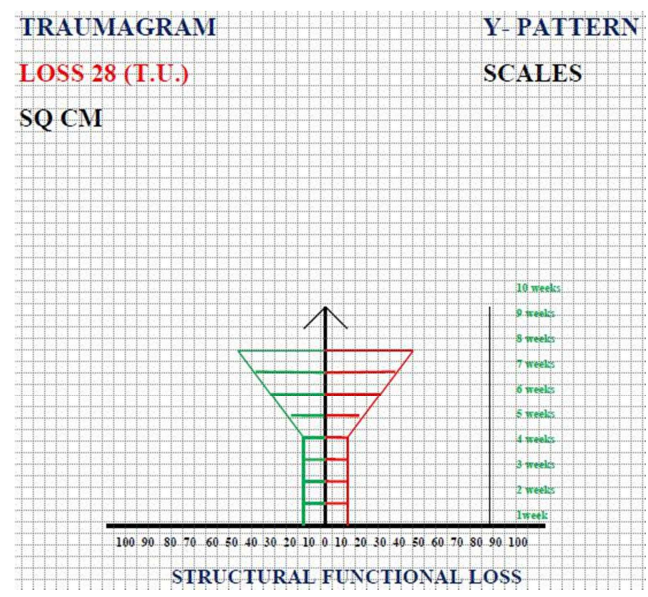

Figure 4. Y PATTERN.

$\mathrm{H}$ pattern: this type of traumagram is anticipated if there is hardly any structural or functional recovery with the passage of time.

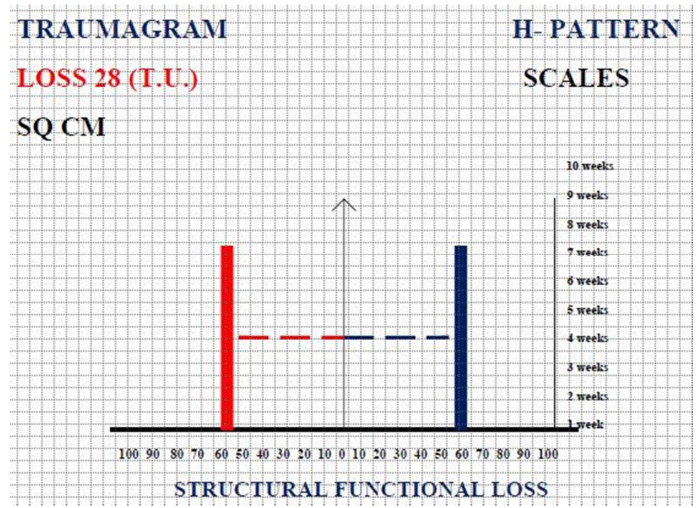

Figure 5. H PATTERN.
$\mathrm{K}$ pattern: In this type there is regular structural loss. Functioinal loss is maximumin the beginning and may recover. However again functional change may start appearing. Similarly there could be a reverse K pattern where functional loss goes on increasing. Structural loss decreases initially but increases again.

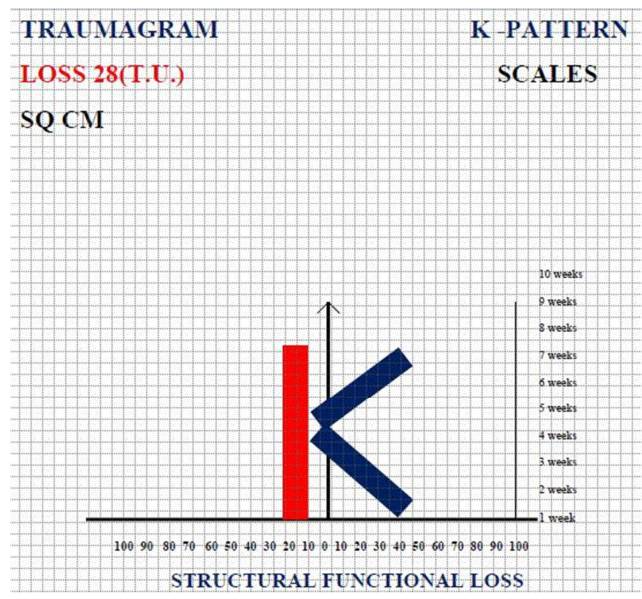

Figure 6. K PATTERN.

L pattern: Rarely there may be only structural loss without any functional loss. Thismay result in $\mathrm{L}$ pattern of traumagram conversely there may be only functional loss without any structural loss. This would result in reverse L pattern of ocular traumagram.

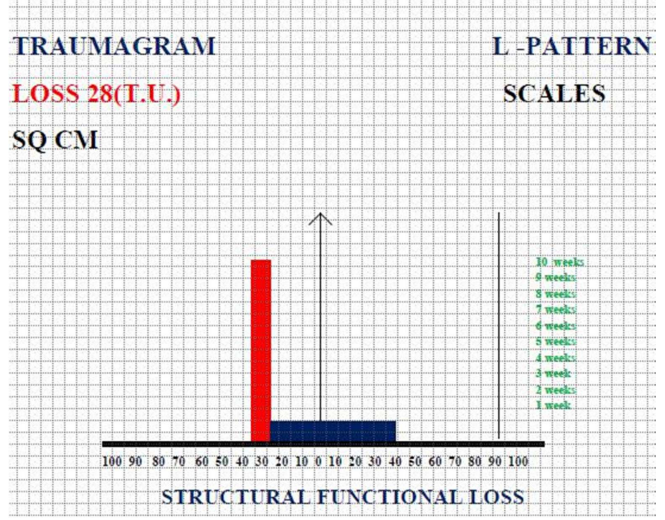

Figure 7. L PATTERN.

M. Irregular pattern: This type may not conform to any type of recognizableshape or size whatsoever.

All the above pattern of traumagrams are constructed on a graph paper and the value of each traumagram is calculated in Trauma Units (T.U.).

\section{Discussion}

It may be pointed out that in these traumagrams bold lines have been drawn to make the figures readily understandable. Actually only the principle involved is highlighted. Before discussing the traumagrams it is necessary to know the methods of calculating structural and functional losses. 
In calculating structural loss various lesions of conjunctiva, cornea, orbit, lids, lacrimal apparatus and globe are recorded. Each of these could be mild, moderate or severe (Table 1). Mild lesions are counted as 1, moderate as 2 and severe as 3 . Then numbers of all the columns are added up. If the total is up to 20 the loss is mild (20\%), if between $21-40$ it is moderate $(40 \%)$, if between $41-60$ it is severe $(60 \%)$, between $61-80$ it is very severe $(80 \%)$ and if the score is above 80 the loss is taken as absolute $(100 \%)$.

Calculation of functional loss is mainly dependent on visual acuity (Table 3). As trauma is most commonly seen in children and young people, it is presumed that the visual acuity was normal before trauma (6/6). In such cases loss of vision after trauma is reliable indicator of functional loss. Post trauma visual acuity is graded in steps of $10 \%$ from $6 / 6$ to $6 / 60$. From $6 / 60$ to No P. L. it is graded in steps of $5 \%$. However post traumatic visual acuity is reduced to $80 \%$ of its value. (Table 4). $5 \%$ value is added for each parameter like visual field, ocular motility, ocular tension and lacrimal dysfunction. This would complete functional loss $(80 \%+20 \%)$.

Such structural loss in $\%$ and functional loss in $\%$ have to be recorded every week for at least 8 weeks. After that the upper ends of the structural loss line and functional loss are joined. The area thus enclosed is termed Ocular Traumagram. The number of sq.cm.enclosed are counted. Each sq.cm.represents 1 Trauma Unit (T. U.). Thus total quantitative estimation of trauma can be done at different levels of time in a given case of trauma. Many authors have attempted to quantify medical data from qualitative estimation in different situations Dua H. S. [5], Crouch E. [6], Yadav M. [7], Hutton W. [8 D. C., Coleb], Fletcher rander A [9], Agrawal P, Mehta D. K. [10].

\section{Conclusions}

Every new technique looks clumsy and time taking in the beginning and one tends to question its utility. Ocular trauma has a very large scope involving almost all ocular structures in a variety of ways. Qualitative estimation could be very variable from person to person and there is no way to compare the magnitude and importance of different cases in different studies of the subject. Hence if this modality comes into practice it is likely to play an important role in evaluation of trauma cases quantitatively. It would help in comparing two studies in a precise manner. It will also measure precisely the improvement or deterioration in a case.

At the outset it would give quantitative assessment to classify a case. It would also help to see the progress of a case and the effect of any treatment medical or surgical. From the pattern of traumagram future course of the condition can be predicte. In medico-legal cases it would be of great value to decide the quantum of compensation and punishment in a case of ocular trauma which is very vague at present. So far in assessment of damage only eye ball is considered whereas in this method damage to ocular adnexa is also calculated. A disease is after all a quantum of loss of structure and/or function. Thus in future it may be possible to assess the quantitative damage in other diseases also. At present only the concept is beingpresented.
Study in actual cases is being carried out and it is hoped to assess its utility more precisely in future.

\section{Acknowledgements}

I am grateful to Mr. ChiranjibMajumder, Associate Professor and Mr. Shivaram Male Assistant Professor in School of Optometry, R.J.N. Ophthalmic Institute, Gwalior for their very valuable help in preparing the paper. I wish to express my deep gratitude to Dr. PurendraBhasin and Dr. PriyamvadaBhasin, Directors of RatanJyotiNetralaya, Gwalior for their help and encouragement. I am also thankful to Mr. Vikas Savita and Aneesh for final correction.

\section{Funding}

No funding received from any source.

\section{Conflict of Interest}

The author declares that he has no competing interest

\section{References}

[1] Shukla B, Khanna B. Trauma index-a system of evaluation of ocular damage due to trauma. Indian J Ophthalmol. 1983;31: 439-41

[2] Kuhn F, Richard M, Loretta M, Robert M. et al. The O. T. S.; Predicting the final vision in the injured eye, p. 9-13; In Ocular Trauma, Principles and Practice, Kuhn F, Pieramici D. J. Thieme, New York, 2002

[3] Blakeslee W. D. Medicolegal issues, Relationship between percentage of vision loss and compensation. P. 37; In Ocular Trauma, Principles and Practice, Kuhn F, Pieramici D. J., Thieme, New York, 2002

[4] Shukla B. Measurement of anterior segment of eye ball in emmetropia, ametropia and Primary glaucoma, Ind. J. Ophthal. 1978; 25, IV: 6-16

[5] Dua H. S., Kiing A. J., Joseph A. A new classification of ocular surface burns. Brit. J. Ophthalmol, 2001; 85: 1379-83

[6] Crouch E, Crouch E. Hyphema, Chapter 8, p. 35-39. In Clinical diagnosis and Managementof Ocular Trauma, Jaypee Brothers, Medical Publishers, St. Louis, 2009

[7] Yadav, M. Compensation in ocular injuries. In Ocular Trauma, a comprehensive text by D. K. Mehta, CBS Publishers and distributors, New Delhi, 2015, $1^{\text {st }}$ Ed., 266-275

[8] Hutton W. L., Fuller D. G. Factors influencing final visual results in severely injured eyes. Amer. J. Ophthal. 1984, 97: 715-22

[9] Fletcher D. C., Colenbrander A, Rehabilitation of patients with ocular trauma:In OcularTrauma, Principles and Practice, Kuhn F and Pieramici D. J., Chapter 6, Thieme Publication, Italy, 2002, p. 31

[10] Agrawal P and Mehta D. K. Ocular injuries due to physical agents: In Ocular Trauma, C. B. S. Publishers \& Distributors, New Delhi, 2015, p. 31 